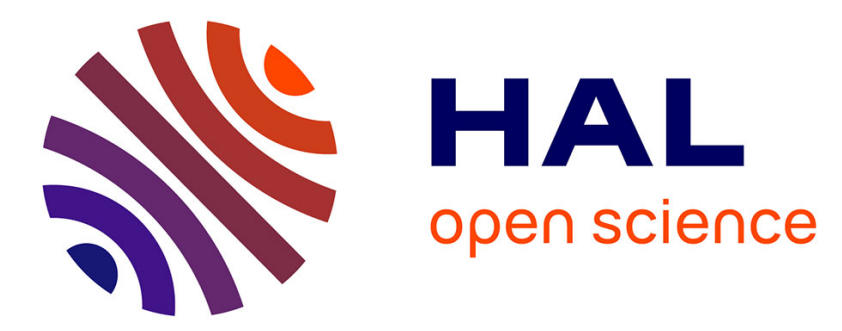

\title{
Lung cancer screening: French radiologists should prepare for it
}

Mathieu Lederlin, Constance de Margerie-Mellon, Samia Boussouar, Sébastien Bommart, Caroline Caramella

\section{> To cite this version:}

Mathieu Lederlin, Constance de Margerie-Mellon, Samia Boussouar, Sébastien Bommart, Caroline Caramella. Lung cancer screening: French radiologists should prepare for it. Diagnostic and Interventional Imaging, In press, 10.1016/j.diii.2021.02.004 • hal-03157306

\section{HAL Id: hal-03157306 https://hal.science/hal-03157306}

Submitted on 3 Mar 2021

HAL is a multi-disciplinary open access archive for the deposit and dissemination of scientific research documents, whether they are published or not. The documents may come from teaching and research institutions in France or abroad, or from public or private research centers.
L'archive ouverte pluridisciplinaire HAL, est destinée au dépôt et à la diffusion de documents scientifiques de niveau recherche, publiés ou non, émanant des établissements d'enseignement et de recherche français ou étrangers, des laboratoires publics ou privés. 
Mathieu Lederlin ${ }^{\mathrm{a}, *}$

Constance de Margerie-Mellon ${ }^{\mathrm{b}, \mathrm{c}}$

Samia Boussouar ${ }^{\mathrm{d}}$

Sébastien Bommart ${ }^{\mathrm{e}}$

Caroline Caramella ${ }^{\mathrm{f}}$

\section{Lung cancer screening: French radiologists should prepare for it}

\author{
Keywords: \\ Lung neoplasm \\ Early detection of cancer \\ Multidetector computed tomography \\ Solitary pulmonary nodule \\ Multiple pulmonary nodules
}

It is always frustrating for a radiologist to diagnose lung cancer at an advanced stage when the same cancer identified at an early stage could have been treated curatively. This clinical situation, which is unfortunately not so rare, highlights the major role of lung cancer screening (LCS) with low-dose computed tomography (LDCT), which is to identify lung cancer at a subclinical stage when surgical resection is still possible.

Despite dramatic therapeutic advances over the last decades, lung cancer remains the first cause of cancer deaths, with 33,000 deaths in 2018 in France. Because there is no sensory innervation in the lung parenchyma, lung cancer develops indolently, during a pre-clinical phase that spans several years for non-small cell lung cancers. Indeed, the mean duration of the preclinical stage (i.e., the period between stage IA when the cancer becomes visible on CT, and stage IIIA considered as the last operable stage) is estimated between 3 and 4 years for non-small cell carcinomas [1]. This offers an opportunity to detect asymptomatic lung cancer through screening. The potential of LCS to reduce lung cancerrelated mortality has been demonstrated by two large prospective randomized trials (i.e., the National Lung Screening Trial and the NELSON trial), showing $20 \%$ and $26 \%$ reduction in lung cancerrelated mortality, respectively $[2,3]$. However, the implementation of LCS is complex with some issues such as the integration of risk prediction models in the selection of participants, the optimization of screening intervals, adherence to screening, or the evaluation of the cost-effectiveness, without forgetting the need to train many radiologists to the specific task of LCS. It is indeed very important to ensure that LCS is practiced with the same level of quality than those in the trials that have proven its value.

In this issue of Diagnostic $\mathcal{E}$ Interventional Imaging, a panel of leading pulmonologists and radiologists has provided a

Abbreviations: CAD, Computer-assisted decision; CT, Computed tomography; INCa, National Cancer Institute; LCS, Lung cancer screening; LDCT, Low-dose computed tomography; SIT, Société d'Imagerie Thoracique (French Society of Thoracic Imaging). comprehensive review of LCS using LDCT [4]. These experts support individual screening as it is already practiced, but most importantly, they urge the setting-up of pilot programs in order to prepare the implementation of LCS at a larger scale. It is estimated that the generalization of LCS in France would prevent 2200 to 7400 deaths per year [5]. While general practitioners and pulmonologists should identify eligible individuals, explain the benefits and risks of LCS and promote LCS and tobacco cessation, radiologists are the guarantors of CT standardization, both for acquisition (image quality, dose) and interpretation (nodule detection, characterization based on volumetric analysis, application of guidelines for follow-up or referral to multidisciplinary team). The implementation of population screening programs will require participation of a large number of radiologists, who will need to be fully aware of the challenges of LCS and trained beforehand.

The French Society of Thoracic Imaging (SIT) has experts involved in LCS, and the new board of the SIT will make LCS a priority for the upcoming mandate. Starting from January 2021, the SIT offers all French radiologists wishing to train at LCS, a series of e-learnings dedicated to LCS. These e-learnings will be followed by hands-on workshops regarding the use of computer-assisted decision (CAD) algorithm for detection and lung nodule volumetry, with the first sessions scheduled for June 2021. In parallel, a project for a national platform hosting the French LCS national database is being considered. Finally, the French Radiological Society and the SIT encourage pilot studies evaluating population-based LCS programs. The CASCADE study (dépistage du CAncer du poumon par SCAnner faible DosE chez les femmes [LCS with LDCT in women]) has received a funding of $€ 1.8 \mathrm{M}$ from the French Ministry of Health and the National Cancer Institute (INCa) and will involve radiologists and pulmonologists from 4 French cities (Paris, Rennes, Grenoble and Betthune). The purpose of this study is to demonstrate that general radiologists trained at LCS and assisted by CAD and artificial intelligence tools, have performances similar to those of double reading by experts. Double reading has been adopted in most screening trials but is not realistic on a large scale. The originality of the CASCADE study is that the cohort of participants will be entirely female (the risk of lung cancer being higher in women than in men with the same smoking history) assuming that the benefit of LCS being probably higher in women [3]. The CASCADE study also includes an economic evaluation to estimate the overall cost of the program, the average cost per participant and the cost per screened participant. Other research projects are highly desirable to improve knowledge in areas that remain insufficiently addressed (e.g., adherence to screening programs, use of ultra-LDCT, feasibility 
of CAD volumetry in routine practice, management of incidental findings, evaluation of markers of cardio-vascular, pulmonary and metabolic risks, benefit of radiomic analysis and deep learning algorithms for the identification of malignant nodules [6-9].

To improve survival, LCS with LDCT is probably more effective and less expensive than systemic treatments. By being trained in LCS and by offering regional experiences, radiologists have the opportunity to participate in reducing mortality from lung cancer. We therefore call on French radiologists to be at the forefront of LCS in the coming years.

\section{Funding}

This work did not receive any grant from funding agencies in the public, commercial, or not-for-profit sectors.

\section{Authors' contributions}

All authors attest that they meet the current International Committee of Medical Journal Editors (ICMJE) criteria for Authorship.

\section{Disclosure of interest}

The authors declare that they have no competing interest.

\section{References}

[1] Ten Haaf K, van Rosmalen J, de Koning HJ. Lung cancer detectability by test, histology, stage, and gender: estimates from the NLST and the PLCO trials. Cancer Epidemiol Biomarkers Prev 2015;24:154-61.

[2] National Lung Screening Trial Research Team, Aberle DR, Adams AM, Berg CD, Black WC, Clapp JD, et al. Reduced lung-cancer mortality with low-dose computed tomographic screening. N Engl J Med 2011;365:395-409.

[3] de Koning HJ, van der Aalst CM, de Jong PA, Scholten ET, Nackaerts K, Heuvelmans MA, et al. Reduced lung-cancer mortality with volume CT screening in a randomized trial. N Engl J Med 2020;382:503-13.

[4] Couraud S, Ferretti GR, Milleron B, Cortot A, Girard N, Gounant V, et al. Intergroupe Francophone de Cancérologie Thoracique, Société de Pneumologie de Langue Française, and Société d'Imagerie Thoracique statement paper on lung cancer screening. Diagn Interv Imaging 2021;102, http://dx.doi.org/10.1016/j. diii.2021.01.012.
[5] Gendarme S, Perrot É, Reskot F, Bhoowabul V, Fourre G, Souquet PJ, et al. Economic impact of lung cancer screening in France: a modeling study. Rev Mal Respir 2017;34:717-28.

[6] Beregi JP, Greffier J. Low and ultra-low dose radiation in CT: opportunities and limitations. Diagn Interv Imaging 2019;100:63-4.

[7] Ludes C, Labani A, Severac F, Jeung MY, Leyendecker P, Roy C, et al. Ultra-lowdose unenhanced chest CT: prospective comparison of high $\mathrm{kV} /$ low $\mathrm{mA}$ versus low kV/high mA protocols. Diagn Interv Imaging 2019:100:85-93.

[8] Waymel Q, Badr S, Demondion X, Cotten A, Jacques T. Impact of the rise of artificial intelligence in radiology: what do radiologists think? Diagn Interv Imaging 2019:100:327-36.

[9] Blanc D, Racine V, Khalil A, Deloche M, Broyelle JA, Hammouamri I, et al. Artificial intelligence solution to classify pulmonary nodules on CT. Diagn Interv Imaging 2020;101:803-10.

Mathieu Lederlin ${ }^{\mathrm{a}, *}$ Constance de Margerie-Mellon ${ }^{\text {b,c }}$ Samia Boussouar ${ }^{d}$ Sébastien Bommart ${ }^{\mathrm{e}}$ Caroline Caramella

a Department of Radiology, University Hospital of Rennes, University of Rennes, 35033 Rennes, France

${ }^{\mathrm{b}}$ Department of Radiology, Hôpital Saint-Louis, Assistance Publique-Hôpitaux de Paris, 75010 Paris,

France

c Université de Paris, 75010 Paris, France

${ }^{\mathrm{d}}$ Department of Radiology, Hôpital de la Pitié-Salpêtrière, Assistance Publique-Hôpitaux de Paris, Sorbonne University, 75651 Paris, France e Department of Medical Imaging, University Hospital of Montpellier, University of Montpellier, 34295 Montpellier, France

f Department of Radiology, Hôpital Marie Lannelongue, Institut d'Oncologie Thoracique, Paris-Saclay University, 92350 Le Plessis-Robinson, France

* Corresponding author. E-mail address: mathieu.lederlin@chu-rennes.fr (M. Lederlin) 